\title{
CUTTING THE INCREMENT
}

\author{
by Muskeg Pete
}

Of late years we have been cheered by the good news that in some parts of the country the amount of wood that the operator is to be allowed to cut is to be limited by the increment. Further, that only part of the increment is to be taken to ensure that the stocking of our forests is gradually built up and to allow, it is supposed, for depletion other than cutting. Personally, this cheered me immensely as indicating a long step in the right direction.

However, as I am a confirmed pessimist I ran true to form and did a little further investigating. It seems that while the operator is to be confined to a cut of 80 per cent of the increment, it is his task to determine what the increment really is. This reminds one greatly of the rural school board which resolved to build the new schoolhouse using the logs of the old schoolhouse, but using the old schoolhouse until the new schoolhouse was built!

Cutting the increment! - on what? Increment is another word for rate of growth and rate of growth predicates, within limits, a certain stable condition of both the forest composition and management.

It presupposes that some conscious effort is to be made at the time of cutting to ensure a continuation of growth of species which have been utilized. Either that or the supposition is made that the new crop after cutting will be of the same composition, and will grow at the rate as the one just removed, no matter in what manner the crop is removed.

Let us examine some of the conditions in our pulpwood stands and the method of cutting to see if conditions following cutting are likely to result in composition and growth similar to the original stands.

We will take first of all the yellow birch-balsam spruce type. In spite of what was said by Graham in the June "Chronicle," the problem of this type is of great importance to the principal pulpwood operators, since they are holding, or were at least some time ago, very large areas of this type under license, hoping at some time to obtain another cut of pulpwood. In any event to say that it is "fortunate that this type occupies only a small proportion of their limits" is a very selfish point of view. This type occupies thousands of square miles of the most accessible and most productive forest land in Eastern Canada. Some of the most important mills are located now adjacent to these areas, and were originally located with this source of supply as a background. Because it has been cut over in such a manner, owing to economic conditions, 


\section{FORESTRY CHRONICLE}

that its present possibility as a source of raw material is handicapped, is no reason for eliminating it in increment calculation. Much has been written and much concern is taken over the possibility of logging inaccessible areas in the north, which means increased cost of the raw material for the pulp mills. It is possible that a much larger return of invesiment might be obtained from improvement of these more accessible forests.

But to return to increment discussion. We now know because these yellow birch-conifer stands have been cut long enough to show results, that cutting the increment (of conifers) is in the case of this type a foolish expression. The original cut would have been very scanty indeed if based on what we know now is the coniferous increment following cuttings, or if based on the quantity and age of the stand, the cut would have resulted in gross overcutting. The huge yellow birch, which has resulted from the close cutting for conifers alone, forms a dense crown cover under which is a stand of suppressed conifers varying from reproduction size to half gown material. Much of the yellow birch itself is worthless except for fuelwood as it is, to a very large extent, defective. To expect that this material will soon die is trusting too much to the will of Providence-they are slowly dying for the last hundred years of their lives.

Next let us examine the pulpwood forests from which some of the large companies are presently drawing their supply. The black spruce type supplies some of the best pulpwond now being cut. It varies a great deal in the rate of growth since in the northern districts climate has much to do with its representation on many different sites which further south would be occupied by other species. But generally speaking it is the slow growing swamp type. As a rule, it has escaped fire, so that its origin must have been a slow development through the ages. On account of its slow growth and more or less pure condition, the only presently apparent method of logging is to clear cut it. What will happen after cutting? Since it has never been cut before and since it has never been started anew from fire, its subsequent development aftor cutting is almost non-predictable. To say that another forest of similar size and age (say 150-180 years of age) will take its place is a mere guess. It has been shown that the advance growth which is nearly everywhere present is almost totally from layers. Will these develop into a forest similar to the one cut? No one knows and consaquently no prediction of increment, accurate enough on which to base the quantity to be cut, can be made.

The next source of pulpwood is the far-famed and much touted white birch-poplar-conifer type, with which may be linked the pure balsam-spruce forest of northern Canada. Much has been made of the fact that the two hardwood species in the mixed part of this type are intolerant and usually act as nurse crops to the conifers. For these reasons wheth- 
er in the mature stand or on the cut-over areas, the hardwoods will have nothing like the effect of the yellow birch as described above. The feeling of optimism in regard to the future of this type when logged for pulpwood, may be partly due to the re-action from the deep pessimism experienced when the results of cutting in the yellow hirch-conifer type became apparent. At least it appeared that no such active forest improvement. measures would be necessary as evidently are in the latter type, if the forest is to be left in shape for future softwood production. The intolerant harwoodconiferous forests may nearly all be assigned to origin by either fire or some wholesale insect attack as the budworm, hemlock looper or other insect. As Graham says "the practice of removing the conifers . . . while leaving the paper-birch standing may probably he regarded as silviculturally blameless" because the original stand came up through the birch and poplar and may $b$ : expected to do so again "at the cost of $\mathrm{m}$ m more than some morc or less serious retardation." However, again we ha\%e the fact that these stands were not cut-nve: before but originated from fire or other catastrophe. These are not similar treatments, i.e., partial cutting of the coniferous element of the stands, and fire. In the case of the latter, the forest floor is usually left bare while a certain amount of standing seed trees of the larger diameters are often left standing. Do the present cutting methods result in the same initial conditions? They do not. Therefore, prediction of increment cannot be made on the basis of the growth of the old stand. It may be, that on the average, only one-half to two-thirds the time it took to produce the old crop may be necessary. But again, it may be found that since the stand has not been started over again as is the case with fire, the successional change towards the climax type, which is constantly operating may induce the formation of a very different type of forest or one in which the various components have different values ${ }^{2}$. The same may be true of our huge areas laid waste by the budworm. The spruce budworm on these areas confined its huge appetite to balsam fir, leaving here and there single trees and islands of spruce throughout the dead stand. Is it imagined that this destruction as a substitute for fire or partial cutting will have the same effect and result in the same kind of stant and the same rate of growth? I would appear again that calculation of the allowable cut by the increment is impossible because the latter in unpredictable.

It has been said that cut-over lands in this type are mostly burned subsequent to cutting. I wonder how true this statement is. While frequently the case that fires do run over part of old cutting areas, this condition cannot be looked upon as a normal feature or process of inanagement. If such were so conservative cutting methods such as diameter limits for the various species, as well as any other silvicultural measures, are useless. But even if it be admitted 
that the natural fate of all cut-over lands in this type is to be burned, this only complicates the problem. The effect of fire subsequent to cutting is not the same as fire in the uncut forest. In fact forest conditions obtaining after fire under any conditions are so varied as to be unpredictable and to expect a forest similar to the one obtaining previous to fire or to cutting followed by fire, is contrary to known facts.

The fact of the matter is the pat phrase of "cutting the increment" or part of it, is fooling ourselves into thinking we have information when this is not the case. Calculation of increment cannot be made without a conscious management plan and at least rudimentary silvicultural treatment-plus data on the result of such management and treatments.

Now look where I've ended. I feel like the man whose wife undertook to spend 80 per cent of his salary cheque, without knowing he'd been fired. At least this discussion may have some value in pointing out the difficulties of increment prediction, and emphasizing the need for continuous experimentation and research so that we may be better equipped to take an authoritative stand on the determination of the annual cut necessary to preserve the producing power of our forests and to augment it.

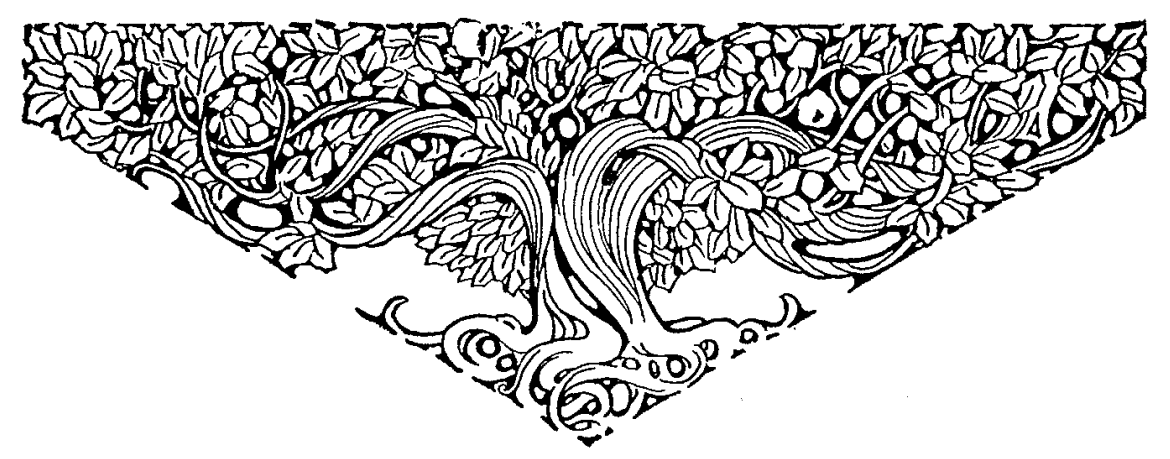

